NBER WORKING PAPER SERIES

THE LIMITED VIABILITY OF

DUAL EXCHANGE-RATE REGIMES

Jacob A. Frenke1

Assaf Razin

Working Paper No. 1902

NATIONAL BUREAU OF ECONOMIC RESEARCH

1050 Massachusetts Avenue

Cambridge, MA 02138

Apri1 1986

This paper was written during the Summer of 1985 while J. A. Frenkel was a visiting professor at the Department of Economics and Fellow of the Sackler Institute of Advanced Studies at Tel-Aviv University, Israel. A previous version entitled "Aspects of Dual Echange-Rate Regimes" appeared as Seminar Paper No. 335, Institute for International Economic Studies, Stockholm, Sweden, September 1985. We wish to thank Joshua Aizenman, Elhanan Helpman and Torsten Persson for useful comments. The research reported here is part of the NBER's research program in International Studies. Any opinions expressed are those of the authors and not those of the National Bureau of Economic Research. 
NBER Working Paper \#1902

Apri 11986

\section{The Limited Viability of Dual Exchange-Rate Regimes}

\section{ABSTRACT}

This paper examines the viability of dual exchange-rate regimes. Typically, under such a regime the exchange rates applicable to current-account (commercial) transactions and to capital-account (financial) transactions differ from each other. This difference may be determined in the free market if the authorities peg the commercial exchange rate and set a binding quota on external borrowing, or it may result from direct pegging of both exchange rates. The analysis starts with a specification of the characteristics of the distortion introduced by the exchange-rate premium (that is, the percentage discrepancy between the financial and the commercial exchange rates), and then provides explicit formula for the equilibrium premium, for its evolution over time and for the welfare cost induced by the distortion. The paper outlines the set of policy options consistent with sustaining a permanently viable dual exchangerate system and highlights the severe constraints that intertemporal solvency requirements of the private sector and of the government impose on the long-run viability of the regime. The paper concludes with an analysis of the monetary changes associated with dual exchange-rate policies and draws the implications of such a regime for the intertemporal distribution of taxes and for the intergenerational distribution of welfare

Jacob A. Frenkel Department of Economics University of Chicago 1126 E. 59th Street Chicago, IL 60637 (312) $962-8253$
Assaf Razin

Department of Economics

Tel-Aviv University

Ramat-Aviv, Te1-Aviv 66978

ISRAEL

(972) - 3-420-733 


\section{Introduction}

This paper deals with the economics of dual exchange-rate regimes. Multiple exchange-rate arrangements have been adopted by numerous countries on various occasions. Departures from a unified exchange-rate regime have taken different forms including multiple exchange rates for different types of commercial transactions, as well as separate exchange rates for commercial and financial transactions; the latter is referred to as a dual (or a two-tier) exchange-rate regime. 1

The adoption of a dual exchange rate regime, taken by itself, introduces a distortion into the economic system. Its adoption has been justified, however, on several grounds. First, it has been argued that in circumstances of inflation and capital flight (induced by expected depreciations of the currency) the separation of the commercial exchange rate from the financial rate facilitates a reduction in capital flight through a change in the finan-i cial exchange rate while avoiding adverse inflationary consequences. Second, it has been argued that in circumstances of inflation and trade-balance deficits, the adoption of dual exchange rates permits commercial exchange-rate policies aimed at the trade balance without providing capital gains on foreign-currency linked assets. In contrast, under a unified exchange-rate regime a devaluation of the currency provides capital gains to owners of foreign-currency linked assets. These capital gains stimulate spending and hamper efforts to contain inflation and to improve the balance of payments. A third argument used to justify dual exchange rates focuses on their impact on relative rates of return and capital flows. Taxes on capital flows, quantitative restrictions on international financial transactions, and dual exchange rates all influence the relative rates of return on domestic and foreign investments. Therefore, it is argued, dual exchange rates may be viewed as an instrument of balance of payments policies. ${ }^{2}$ Additional arguments concerning 
the welfare implications of dual exchange-rate regimes have also been developed in the contexts of the analyses of second-best policies and public finance. ${ }^{3}$

The literature dealing with the working of dual exchange-rate regimes examined the determinants of the free financial exchange rate. Issues analyzed in this context concerned the effects of fiscal, monetary, and commercial exchange-rate policies on the free financial exchange rate, on the real exchange rate and on the current account of the balance of payments. 4 In analysing these central issues, previous contributions have employed a great diversity of models while the links among which have not been always spelled out. This paper develops a unified framework in order to reexamine some of these issues in an attempt to clarify and identify the mechanisms governing the operation of dual exchange-rate regimes. We specify the precise nature of resultant distortions and provide an exact measure of the welfare cost. In characterizing the dual exchange-rate regime we assume that the commercial exchange rate applicable to transactions in the balance of trade is pegged and we exanine two alternative formulations concerning the financial exchange rate. In the first formulation the government sets a binding quota on the volume of external debt and the financial exchange rate is determined in the free market. With a binding quota the equilibrium financial exchange rate exceeds the pegged commercial rate; the percentage discrepancy between the two is defined as the dual exchange-rate premium. Our analysis provides an explicit formula for the equilibrium premium as well as for its evolution over time. In the second formulation the government pegs the dual exchange-rate premium (through pegging the paths of both the commercial and the financial exchange rates) but allows for a free mobility of capital. In this case our analysis provides an explicit formula for the equilibrium path of external debt. 
Since our model is characterized by sophisticated forward looking and fully informed individuals, a natural question is whether the dual exchangerate system is viable. Specifically, since both the government and the private sector must be solvent we examine the constraints that long-run viability imposes on the management of the dual exchange rate system. We show that there is a limited set of policy options consistent with a permanently viable dual exchange-rate system. For example, we show that unless the dual exchange-rate premium or the quota on foriegn debt are set at a level which eliminates asset accumulation, a policy that fixes permanently the premium or the quota cannot be sustained indefinitely without violating the solvency constraints. 5 On the other hand a transitory adoption of a dual exchange rate regime is of course possible. We examine the relation between the length of the period during which the dual exchange rate system is in effect and the magnitudes of the premium and of the external debt. In considering the adoption of a dual exchange-rate regime the limitations imposed by the intertemporal solvency constraints on the long-run viability of the system are added to the difficulties associated with the separation between the commercial and the financial exchange markets. The segmentation difficulties are present in both the short run and the long run. 6

Our model does not provide a rationale for the adoption of a dual exchange rate regime. Rather, in order to clarify the working of the system and to identify the distortions arising from its adoption we start from a distortion-free economy and examine the implications of introducing a dual exchange-rate regime. ${ }^{7}$

In section II we develop a benchmark model posessing the Ricardian equivalence property. Accordingly, the timing of the monetary injections associated with the management of the dual exchange-rate system does not influence the real equilibrium. In the benchmark model the management of the 
dual exchange-rate regime affects the equilibrium through the induced differentials between domestic and world real rates of interest. In section III we extend the benchmark model to a framework in which the Ricardian equivalence does not hold. This is achieved by allowing for overlapping generations with a finite horizon. In that case the management of the dual exchange-rate regime impacts on the equilibrium not only through influencing real interest-rate differentials but also through influencing the timing of monetary injections and international reserve movements. Hence, under such circumstances the dual exchange-rate regime inflicts the usual distortions and in addition, the management of the regime directly influences the exchangerate premium, the intergenerational distribution of wealth, and welfare. Specifically, we examine the circumstances under which a rise in the commercial exchange rate (a devaluation) leads to overshooting or undershooting of the market-determined financial exchange rate. This analysis provides information about the effects that commercial exchange-rate policies exert on the premium. Hence, by focusing on the temporary nature of the dual exchange-rate regime and by highlighting the links between the regime and the intertemporal distribution of effective taxes and distortions, we introduce pertinent intergenerational considerations into the analysis of dual exchange-rate systems. Finally, section IV contains concluding remarks.

\section{The Benchmark Model}

In this part of the paper we sketch the benchmark model for the analysis of dual exchange-rate regimes. In order to highlight the key issues we focus on two alternative (but to a large extent equivalent) formulations of such regimes. In both the exchange rate applicable to commercial transactions passing through the trade account of the balance-of-payments is pegged. The two formulations differ in their specification of the regulations concerning 
financial transactions. The first assumes that the government imposes a quota on the volume of the international flow of financial assets. In that case the financial exchange rate is determined in the free market at a level that may differ from the pegged commercial rate. Our analysis examines the precise determinants of the differential between the two rates. This differential is referred to as the premium. The second formulation assumes that the government sets different paths for the commercial and the financial exchange rates. In that case the premium is determined by policy and the volume of capital-account transactions is determined by the free market. In this context we determine the constraints on the range of feasible paths of the two exchange rates. These constraints arise from the requirement that the government and the private sector must be solvent.

Our benchmark model, which is designed to yield Ricardian equivalence results, assumes a small open economy with one composite traded good and undistorted taxes. These assumptions are modified in subsequent sections. The key building blocks of the model are (i) a specification of the private sector's budget constraints and behavioral functions; (ii) a specification of the government budget constraint and (iii) the determination of equilibrium.

\subsection{The private sector}

Consider a representative individual operating in an environment governed by a "cash-in-advance" convention according to which purchases of domestically produced goods are paid for with domestic currency while purchases of foreign produced goods are paid for with foreign currency. The cash-in-advance model allows great precision in tracing out the monetary and exchange rate policies all the way through, and it introduces no distortions in conjunction with the monetary policy per se. This enables us to isolate the effects of the dual 
exchange rate regime. For applications of such a convention see Helpman (1981), Helpman and Razin (1982), Lucas (1982), Persson (1984) and Stockman (1980). The infinitely lived representative indivudual faces a sequence of the following periodical budget constraints:

$$
\begin{aligned}
& e_{0} p_{0}^{\star} C_{0}=R-T_{0}+s_{0} B_{0}-s_{0}^{R}-1 B_{-1} \\
& e_{1} p_{1}^{\star} C_{1}=e_{0} p_{1}^{\star} Y_{0}-T_{1}+s_{1} B_{1}-s_{1} R_{0} B_{0} \\
& e_{2} D_{2}^{\star} C_{2}=e_{1} P_{1}^{\star} Y_{1}-T_{2}+s_{2} B_{2}-s_{2} R_{1} B_{1}
\end{aligned}
$$

where $e$ denotes the exchange rate applicable for comercial transactions and $s$ denotes the exchange rate applicable for financial transactions. These exchange rates express the price of forelgn exchange in terms of domestic currency. In equation (1) $p^{*}$ denotes the foreign price of goods, $Y$ measures domestic output, $T$ denotes lump-sum taxes, $B$ denotes the private-sector's one-period debt denominated in terms of foreign exchange, $R$ denotes one plus the interest rate applicable to loans in terms of forelgn currency, $C$, denotes the rate of consumption of the composite good and, finally, $\bar{M}$ denotes initial money holdings (the money supply in period $t=-1$ ). The first equation in (1) specifies the budget constraint in period zero. The left-hand-side measures the domestic-currency value of consumption (where we have used the law of one price by which domestic price, $p$, equals $\left.e p^{\star}\right)$. The right-hand-side measures the total amount of available net resources (measured in terms of domestic currency): Initial money holdings minus taxes plus new borrowing minus repayment of interest and principal on previous period one-period debt.

The second budget constraint has a similar interpretation except that it includes the nominal value of period-zero output. This element reflects the 
"cash-in-advance" convention according to which during each period firms accumulate cash balances obtained from the proceeds of output sales and at the end of each period (which coincides with the beginning of the subsequent one) these proceeds are redistributed to individuals as wages and dividends. These money holdings at the beginning of period 1 equal the value of domestic output sales during period zero $\left(e_{0} p_{0}^{\star} y_{0}\right)$. The rest of the constraints in

(1) are interpreted similarily.

Consolidating the budget constraints and making use of the requirement that at the limit all debt must be paid ${ }^{8}$ yields:

$$
\begin{aligned}
& C_{0}+\left(\frac{e_{1}}{e_{0}} \frac{s_{0}}{s_{1}} \frac{p_{1}^{*}}{p_{0}^{*}} \frac{1}{R_{0}}\right) C_{1}+\left(\frac{e_{2}}{e_{0}} \frac{s_{0}}{s_{2}} \frac{p_{2}^{*}}{p_{0}^{*}} \frac{1}{R_{0}^{R} 1}\right) C_{2}+\ldots= \\
& {\left[\left(\frac{1}{R_{0}} \frac{s_{0}}{s_{1}}\right) Y_{0}+\left(\frac{1}{R_{0} R_{1}} \frac{e_{1}}{e_{0}} \frac{s_{0}}{s_{2}} \frac{p_{1}^{*}}{P_{0}^{*}}\right) Y_{1}+\ldots .\right]}
\end{aligned}
$$

$$
\begin{aligned}
& +\left[\frac{\bar{H}-T_{0}}{e_{0} p_{0}^{\star}}-\frac{1}{e_{0} p_{0}^{\star}} \frac{s_{0}}{s_{1} R_{0}} T_{1}-\frac{1}{e_{0} p_{0}^{\star}} \frac{s_{0}}{s_{2} R_{0} R_{1}} T_{2} \ldots .-\frac{1}{e_{0} p_{0}^{t}} \frac{s_{0}}{s_{t} R_{0} \ldots R_{t-1}} T_{t} \ldots\right] \\
& -\frac{s_{0}}{e_{0} p_{0}^{*}}\left(R-1^{8}-1\right) \equiv W_{0}
\end{aligned}
$$

This constraint which defines the initial value of wealth, $W_{0}$, is expressed in terms of units of consumption in the initial period. The economic interpretation of the various terms in (2) is as follows. The term in the parenthesis multiplying $C_{1}$ is the domestic real discount factor applicable for consumption in period one. It is composed of three components. First, the foreign nominal interest factor $\left(1 / R_{0}\right)$; second, one plus the foreign rate of inflation $\left(\mathrm{p}_{1}^{*} / \mathrm{p}_{0}^{*}\right)$ and thus the product $\left(\mathrm{p}_{1}^{*} / \mathrm{p}_{0}^{*}\right) / \mathrm{R}_{0}$ is the foreign real discount factor; and finally the third component represents the ratio of the percentage depreciation of the two exchange rates 
$\left(e_{1} / e_{0}\right) /\left(s_{1} / s_{0}\right)$ (in a continuous time specification this term would be the difference between the percentage rates of depreciation of the two exchange rates). This last component represents the contribution of exchange-rate changes to the real rate of return on investment in financial assets, that is, the capital gain on an investment in assets denominated in foreign currency is $\left(s_{1} / s_{0}\right)$ and its product with $\left(e_{0} / e_{1}\right)$ translates the return to units of foreign-currency denominated goods. Thus, the product $\left(e_{1} / e_{0}\right)\left(s_{0} / s_{1}\right)\left(p_{1}^{*} / p_{0}^{*}\right) / R_{0}$. is the domestic real discount factor applicable to $\mathrm{C}_{1}$. Similar interpretation applies to the coefficients multiplying the rates of consumption in other periods. As is evident, divergencies between the domestic and the foreign real rates of interest stem from the terms involving exchange-rate changes. It is important to note that these divergencies can ". arise only from differences in the percentage rates of depreciations of the commercial and financial exchange rates. In the absence of such a difference, the domestic and foreign real rates of interest are equalized. In that case all allocations replicate those obtained with a completely free world capital market. 9

The term in the parentheses multiplying the levels of output on the right-hand-side of equation (2) also represents present value factors but, as may be seen, these differ from those used to evaluate the sequence of consumption. The difference arises from the underlying "cash-in-advance" assumption according to which nominal proceeds from sales of output are distributed with one period lag. Thus, for example, the ratio of the coefficients of $Y_{1}$ and $C_{1}$ is $\left(s_{1} / s_{2}\right)\left(1 / R_{1}\right)$ which is the foregone nominal rate of return due to the lagged payment. The next group of terms on the right-hand-side of equation (2) represents the sum of the nominal taxes discounted by the nominal rate of interest. Here it is relevant to note that the government, by pegging the 
initial value of the commercial exchange rate, $e_{o}$, influences the real value of this discounted sum. Finally, the last term on the right-hand-side of equation (2) is the real value of the private sector initial debt. We note that the policy choice of $s_{0}$ and, thereby, the initial ratio of the two exchange rates, $s_{0} / e_{0}$ determines the real value of this initial debt commitment. Thus, the foregoing discussion of the various terms in equation (2) shows that there are four policy considerations which affect the budget constraint under a dual exchange rate regime. First, the initial level of the commercial exchange rate, $e_{0}$, second, the initial level of the financial exchange rate, $s_{0}$, third, the difference between the percentage rates of change of the two exchange rates and fourth, the path of taxes.

In a subsequent section we determine the precise equilibrium of the system. In order to obtain simple solutions we continue this sketch by specifying, in equation (3), a logarithmic utility function.

$$
U=\sum_{t=0}^{\infty}{ }^{t} \log C_{t}
$$

where \& denotes the subjective discount factor. Maximization of (3) subject to the consolidated budget constraint (2) yields equation (4) as the consumption function:

$$
c_{t}=\frac{\delta^{t}}{a_{t}} w_{0}
$$

where a denotes the domestic present-value factor which depends on the domestic real rates of interest. Thus,

$$
a_{t}=\frac{1}{R_{0} \cdots R_{t-1}} \frac{e_{t}}{e_{0}} \frac{s_{0}}{s_{t}} \frac{p_{t}^{\star}}{p_{0}^{\star}} .
$$

We note that $a_{t}$ is the reciprocal of the coefficient multiplying 
$c_{t}$ in the consolidated budget constraint in equation (2). The dependence

of $a_{t}$ on the evolution of the two exchange rates implies that government policies concerning the management of the dual exchange-rate system has a direct effect on the intertemporal allocation of consumption and asset accumulation.

\subsection{The Government}

In discussing the government sector it is convenient to separate government transactions into two accounts: a domestic currency account and a foreign currency account. In specifying these accounts we distinguish between the two formulations of the regulations governing international financial transactions.

We begin with the formulation which assumes that the government sets the paths of the two exchange rates and allows free mobility of capital at the prespecified exchange rates. Under these circumstances international financial transactions that are undertaken by the private sector reflect themselves in the domestic-currency account of the government since the latter is comnitted to peg the financial exchange rate. Thus, in period the monetary expansion induced by government foreign exchange intervention in pegging the

financial exchange rate is $\bar{s}_{t}\left(B_{t}-R_{t-1} B_{t-1}\right)$, where $\bar{s}_{t}$ denotes the pegged financial exchange rate. In addition, foreign exchange intervention in pegging the commercial exchange rate corresponds to the trade balance and the monetary expansion that is associated with this operation in period $t$ is $e_{t} p_{t}^{*}\left(y_{t}-C_{t}\right)$. Denoting total monetary injections associated with foreign exchange interventions by $x_{t}$, yields

$$
x_{t}=e p_{t}^{*}\left(Y_{t}-C_{t}\right)+\bar{s}_{t}\left(B_{t}-R_{t-1} B_{t-1}\right)
$$

The second formulation of the regulations concerning international financial transactions assumes that the government imposes a quota on the 
volume of the economy's net international borrowing. Since in our model all debt is of one-period maturity, this constraint amounts to a quota on the size of the economy's external debt. We denote this quota by $\overline{8}_{t}^{*}$. There are many alternative mechanisms and institutional specifications that can bring about the enforcement of such a quota. For example, the government may specify an upper limit on private borrowing from abroad. In that case the comitment to peg the commercial exchange rate at a given leyel implies that the government must stand ready to supply foreign exchange to cover trade deficits. In order to obtain the foreign exchange necessary to peg the commercial exchange rate without increasing its net borrowing from abroad, the government is assumed to purchase the necessary quantity in the local market for foreign exchange (at the free financial exchange rate). It is important to note that the details of this mechanism are introduced only as a convenient example rather than an intrinsic characteristic of this specification of the dual exchange-rate regime. With this formulation the monetary injections associated with foreign exchange interventions are two: purchases of foreign currency in the local financial market and sales of foreign exchange to cover the trade deficit. Accordingly equation (5) becomes

$$
x_{t}=e_{t} p_{t}^{*}\left(Y_{t}-C_{t}\right)+s_{t}\left(\bar{B}_{t}-R_{t-1} \bar{B}_{t-1}\right)
$$

These two alternative formulations of the monetary consequences of exchange rate interventions reflect themselves in the money supply. Accordingly, the money supply in period $t$ can be expressed as the sum of the initial supply $\bar{M}$ and the cumulative monetary injections through exchangerate interventions minus tax receipts:

$$
M_{t}=B+\sum_{j=0}^{t}\left(x_{j}-T_{j}\right)
$$


The government foreign account states that government net external borrowing must equal the trade balance deficit minus the private sector's net external borrowing. Denoting the economy's net external borrowing by $B$ * and noting that $8^{*}$ equals the sum of private and government external borrowing implies that

$$
P_{t}^{*}\left(C_{t}-Y_{t}\right)=B_{t}^{*}-R_{t-1} B_{t-1}^{*}
$$

Consolidating the sequence of the constraints in equation (7) and using the solvency requirement yields

$$
\sum_{t=0}^{-}\left(\frac{p_{t}^{*}}{p_{0}^{\star}} \frac{1}{R_{0} R_{1} \cdots R_{t-1}}\right)\left(C_{t}-Y_{t}\right)=-\frac{1}{p_{0}^{\star}} R_{-1} B^{*}-1
$$

Equation (8) states that the discounted sum of the trade balance (evaluated by using the world real rates of interest) must equal the initial net foreign asset position. 10

\section{II.3. Equilibrium and Distortions of Dual Exchange Rate Regimes}

Equilibrium requires that the demand for money equals the supply. Since in this model with positive nominal rate of interest money is not held as a store of value, the entire money supply is absorbed by firms in exchange for output sales. Thus, the "demand" for money is $e^{\star} Y_{t}$ and in equilibrium

$$
M_{t}=e_{t} p_{t}^{*} Y_{t}
$$

In order to characterize the equilibrium of the system we first express the equilibrium value of wealth, $H_{0}$. The focus on the analysis of $H_{0}$ enables a simple exposition of the nature of the distortions that characterize the dual exchange-rate regime. Further, such an analys is yields insights into the determination of alternative policies that can be used in order to obtain 
equivalent results. Using the right-hand-side of equation (2) along with the government accounts (5) (or (5')) (6) and (7), and the money market clearing condition (9), it is shown in Appendix I that

$$
\begin{aligned}
W_{0}= & {\left[Y_{0}+\left(\frac{e_{1}}{e_{0}} \frac{s_{0}}{s_{1}} \frac{p_{1}^{*}}{p_{0}^{*}} \frac{1}{R_{0}}\right) Y_{1}+\left(\frac{e_{2}}{e_{0}} \frac{s_{0}}{s_{2}} \frac{p_{2}^{*}}{p_{0}^{*}} \frac{1}{R_{0} R_{1}}\right) Y_{2}+\ldots\right]-\frac{R_{-1}}{p_{0}^{*}} B_{-1}^{*} } \\
& +\frac{s_{0}}{e_{0} p_{0}^{*}}\left[\left(\frac{e_{0}}{s_{0}}-\frac{e_{1}}{s_{1}}\right) B_{0}^{*}+\frac{1}{R_{0}}\left(\frac{e_{1}}{s_{1}}-\frac{e_{2}}{s_{2}}\right) B_{1}^{\star}\right. \\
& \left.+\frac{1}{R_{0} R_{1}}\left(\frac{e_{2}}{s_{2}}-\frac{e_{3}}{s_{3}}\right) B_{2}^{*}+\ldots+\frac{1}{R_{0} \cdots R_{t-1}}\left(\frac{e_{t}}{s_{t}}-\frac{e_{t+1}}{s_{t+1}}\right) B_{t}^{*}+\ldots\right] .
\end{aligned}
$$

Equation (10) shows the equilibrium value of $w_{0}$ corresponding to the two alternative formulations of the dual exchange-rate regime which underlie equations (5) and (5'). When the policy is formulated in such a way so as to peg the paths of the two exchange rates, the endogeneous variable that is determined in equilibrium is $B^{*}$ - the economy's net external borrowing (in that case the reader may wish to put an upper bar over the two exchange rates). On the other hand, when the policy pegs only the commercial exchange rate and places a quota over the magnitude of the economy's net external borrowing, the endogeneous variable that is determined in equilibrium is $s-$ the free market financial exchange rate (in that case the reader may wish to put an upper bar over the variables $e$ and $\left.B^{*}\right)$.

This presentation of the equilibrium value of wealth highlights three considerations. First, in comparison with the pricing of consumption in equation (2) (as reflected by the coefficients of $c_{t}$ ), here the pricing of outputs is also done by using the domestic real interest rates. Thus, in contrast with the formulation in equation (2), in equilibrium the lagged payment which reflects the cash-in-advance convention has no effect on the 
pricing of outputs. Second, the benchmark model highlights the consequences of having a forward looking rational consumer who fully internalizes future tax liabilities associated with initial government external debt. Thus, in conformity with the Ricardian proposition, the equilibrium value of wealth nets out the term $\left(R_{-1} B_{-1}^{*} / P_{0}^{*}\right)$. Third, and most important, the unique element introduced by the existence of capital controls and the dual exchange-rate system is represented by the expressions in the last squared brackets on the righ-hand-side of equation (10). This expression denotes the discounted sum of the implicit tax transfers associated with the dual exchange-rate system as perceived (and taken as given) by the rational, forward looking, individuals. Specifically, consider the coefficient of $B_{0}^{*}$ which can also be written as $\left(e_{0} / s_{1}\left(\left[\left(s_{1} / s_{0}\right)-\left(e_{1} / e_{0}\right)\right]\right.\right.$. As argued earlier, this term represents the difference between domestic and foreign real rates of return on financial investment. Thus, if for example, the rate of depreciation of the financial exchange rate exceeds the rate of depreciation of the commercial rate so that $\left(s_{1} / s_{0}\right)$ is larger than $\left(e_{1} / e_{0}\right)$ then with a positive net external debt, $B_{0}^{*}$, there is an implicit subsidy to domestic asset holders. In that case the percentage subsidy rate is $\frac{s_{0}}{e_{0} p_{0}^{*}}\left[\left(\frac{e_{0}}{s_{0}}\right)-\left(\frac{e_{1}}{s_{1}}\right)\right]$ and its product with the "subsidy base", $B_{0}^{*}$, yields the implicit transfer in period zero. The rest of the terms on the right-hand-side of equation (10) have a similar interpretation except that they are discounted to the present by using the world rates of interest. In the case in which the commercial and the financial exchange rates change at the same percentage rate, so that $e_{t+1} / e_{t}=s_{t+1} / s_{t}$, the implicit tax-subsidy rates are zero. In that case there is no divergence between domestic and foreign real rates of interest and the equilibrium value of wealth becomes

$$
w_{0}=Y_{0}+\frac{p_{1}^{*}}{p_{0}^{\star}} \frac{1}{R_{0}} Y_{1}+\ldots+\frac{p_{t}^{\star}}{p_{0}^{\star}} \frac{1}{R_{0} \cdots R_{t} Y_{t}}+\ldots \frac{1}{p_{0}^{*}} R_{-1} B_{-1}^{*}
$$


Thus, in that case the equilibrium value wealth is the discounted sum of current and future incomes net of initial external debt. With equal rates of depreciation the equilibrium replicates the outcome obtained with free open capital account of the balance-of-payments. In that case (and in contrast with equation (10)), the time path of external debt, $B_{t}^{*}$, does not influence the equilibrium value of wealth and consumption. In general, however, the time patterns of external debt, $B^{\star}$, impacts on the real equilibrium.

The foregoing interpretation of equation (10) illustrates two key issues. First, it highlights the fact that the dual exchange-rate regime operates in a manner that introduces implicit taxes on capital flows. It follows, therefore, that such outcomes can also be replicated through explicit taxation of, or quotas on, financial capital flows under a floating exchange-rate regime. Second, our formulation presented the precise manifestation and magnitude of the distortions that are associated with the dual exchange-rate regime.

It is noteworthy that the analysis of the equilibrium value of $W_{0}$ did not employ the specific behavioral assumptions underlyig the utility function (and, thereby, the consumption function). In subsequent sections we will analyze in detail the factors that govern the dynamic evolution of wealth, external debt, and the exchange rates. For this purpose we will need to use the specific behavioral assumptions. In order to set the stage for such an analysis it is convenient to derive the equilibrium relation between external debt, initial wealth and the two exchange rates.

In general, the economy's external debt in period $t$ can be written as the difference between the sums of the present values of past as well as current consumptions and outputs adjusted for the initial debt commitments (in. present value). The compoundings of these quantities are performed as usual by employing the world rates of interest. 
Substituting the consumption function (4) into the economy's budget constraint (7), and solving the difference equation for $B_{t}^{*}$ (for any given value of $W_{0}$ ), yields

$$
\begin{aligned}
B_{t}^{\star}= & \left.(1-\delta) R_{0} \ldots R_{t-1} \cdot p_{0}^{*} W_{0}\left[1+\left(\delta \frac{s_{1}}{s_{0}} \frac{e_{0}}{e_{1}}\right)+\delta^{2} \frac{s_{2}}{s_{0}} \frac{e_{0}}{e_{2}}\right)+\ldots+\left(\delta \frac{s_{t}}{s_{0}} \frac{e_{0}}{e_{t}}\right)\right] \\
- & {\left[R_{0} \cdot R_{1} \ldots R_{t-1} p_{0}^{\star} Y_{0}+R_{1} \ldots R_{t-1} p_{1}^{*} Y_{1}+\ldots+p_{t}^{*} Y_{t}\right] } \\
& +R_{0} R_{1} \ldots R_{t-1}\left(R_{-1} B_{-1}^{\star}\right) .
\end{aligned}
$$

Using the solvency requirement that at the limit (as time goes to infinity) the present value of debt approaches zero, equation (11) becomes

$$
P_{0}^{*} W_{0}=\frac{\sum_{0}^{\infty} \frac{P_{t}^{*} Y_{t}}{R_{0} \cdots R_{t-1}}-R_{-1} B_{-1}^{*}}{(1-\delta) \sum_{0}^{*} \delta{ }^{t}\left(\frac{s_{t}}{s_{0}} \frac{e_{0}}{e_{t}}\right)}
$$

Equations (10)-(12) constitute the system which can be solved in order to yield the entire equilibrium paths of $B_{t}^{*}$, the ratio of the two exchange rates and the equilibrium value of $W_{0}$. These solutions provide a complete characterization of the real equilibrium of the system. The solution of the real system can be used together with equation (2) in order to determine the implied value of the discounted sum of nominal taxes and transfers. As is eyident in the present benchmark model all that matters are discounted sums of the lump-sum taxes and transfers rather than their precise timing. This property reflects the structure of the model which yields Ricardian-equivalence propositions. In a subsequent section we relax some of the assumptions underlying the Ricardian structure. In that case the equilibrium depends on the precise time path of taxes. 
In the next section we analyze the characteristics and the determinants of the endogenous variables under the two formulations of the dual exchange-rate regimes. Thus we examine the evolution of ( $i$ ) the dual exchange-rate premium under the assumption that there is a quota on net external borrowing and $(i i)$ the magnitude of net external borrowing under the assumption that both the commercial and the financial exchange rates are pegged.

\subsection{The Quota on External Borrowing and the Flexible Dual Exchange Rate} Premium

When there is a quota $B_{t}^{*}$ on the path of net external borrowing the authorities are assumed to peg the commercial exchange rate, $e_{t}$, while letting the financial exchange rate, $s_{t}$, be determined in the free market. In equilibrium the market-determined financial exchange rate may differ from the pegged commercial rate. We define the exchange rate premium by the percentage discrepancy between $s$ and $e$; that is, the premium is (s/e)-1. In this section we analyze the determinants of this premium. In addition to attempting to clarify the working of dual exchange rate regimes, our interest in analyzing the determinants of the premium stems from the fact that the assumption that the authorities are capable of separating the markets and preventing arbitrage between the comercial and the financial exchange rates may be rendered invalid if the premium gets too large. Thus, our analys is may be useful for identifying the factors that are releyant for determining whether the dual exchange-rate regime is viable.

In order to gain insights into the factors governing the magnitude of the. exchange-rate premium and the viability of the dual exchange-rate regime we simplify the exposition and divide the horizon into two: the present $(t=0)$ and the future $(t=1, \ldots, \infty)$. We assume that the quota and, thereby, the dual 
exchange-rate regime, are in effect for $\tau$ periods after which the quota is relaxed and the financial exchange rate is unified with the pegged commercial rate. Throughout the future the world rate of interest, and the levels of output and taxes are assumed to be constant. We further assume that the commercial exchange rate is pegged at the level $e=1$ and we define units so as to set the (constant) world price level at unity. In Appendix II we derive the explicit solutions for the equilibrium value of the financial exchange rate. Since the commercial exchange rate is pegged these expressions are also applicable for the analysis of the premium. The solution for $s_{t}$ is:

$$
s_{t}=s_{0}\left[\frac{\left(Y-(R-1) \vec{B}^{\star}\right)}{\left(Y_{0}-R_{-1} B_{-1}^{\star}+\vec{B}^{*}\right)} \frac{R}{R_{0}}\right](R \delta)^{-t} \quad \text { for } t=1, \ldots, \tau \text {. }
$$

Substituting (13) into (12) and (2) (for a large $\tau$ ) yieids a solution for $s_{0}$

$$
S_{0} \cong\left(\frac{1}{(1-\delta)\left(R_{-1} B_{-1}^{*}\right)}\right)\left(\frac{Y-R_{-1} B_{-1}^{*}+\bar{B}^{*}}{Y-(R-1) \bar{B}^{*}}\right)\left(\frac{(R-1)}{R} R_{-1} R_{-1}^{*}-T\right)+\frac{1}{R_{-1} B_{-1}^{*}}\left(M-T_{0}\right)
$$

As is evident, the equilibrium value of the financial exchange rate in period zero which is the domestic price of the foreign-currency linked debt at the beginning of this period depends on the money supply, output, taxes, and the rate of interest as well as on the magnitude of the historically given foreign debt and the size of the quota. In addition, the value of the financial rate also depends on the length of the period $\tau$ during which the quota is in effect. From equation (14) it is seen that during the period for which the dual exchange-rate regime is in effect the initial equilibrium value of the financial exchange rate, $s_{0}$, depends positively on the existing money supply $\bar{M}_{-} T_{0}$ (a stock which was carried over from the previous period net of period zero taxes). 
Likewise, the value of $s_{0}$ depends negatively on the size of the quota on external debt, $\bar{B} *$ (when taxes exceed the initial debt commitment) and on future taxes, T. In general, except for the money stock which exerts a direct effect on the financial exchange rate, the other factors influence the equilibrium value of $s_{0}$ through their influence on the real rate of interest. Those factors which lower the real rate of interest induce an increase in the exchange rate premium and vice versa.

Equation (13) specifies the equilibrium value of the financial exchange rate for all future periods during which the dual exchange-rate regime operates. In addition to providing information on the impact of the various variables on the level of the exchange rate, equation (13) can also be used in order to determine the evolution of the premium over time as well as to assess the likely viability of the dual rate regime.

In this context it is relevant to note that the evolution of the financial rate (as measured by the ratio $s_{t} / s_{0}$ ) does not depend on the length of the period $\tau$. The evolution of the financial exchange rate is explained as follows. The stationary levels of outputs, interest rates and prices imply that as long as the level of the quota is fixed, consumption must be fixed. Obviously, from the consumption function (4) such stationarity is achieved if the real rate of interest equals the rate of time preference. Thus, $s_{t} / s_{t-1}$ must equal $1 / \delta R$, and $x_{t} \equiv s_{t} / s_{0}$ is proportional to $(1 / \delta R)^{t}$.

The assumption that the quota is binding implies that the economy is a dissaver. This implies that the rate of interest is smaller than the subjective rate of time preference and, therefore, that the product $R \&$ is smaller than unity. From equation (13) it is seen that when $R \delta<1$ the financial exchange rate and, thereby, the exchange-rate premium rises over time. Obviously, under such circumstances for a large enough value of I the 
assumption that the authorities can separate the markets and prevent profitable artibrage between the commercial and the financial exchange rates becomes highly questionable. It follows, therefore, that the length of the period $i$, cannot exceed a critical value since otherwise at some future date the size of the quota will have to be modified. Thus the present benchmark model illustrates the difficulties associated with the design of a dual exchange-rate regime which is based on a permanent quota.

In addition to the long run difficulties induced by potential arbitrage, the dual exchange rate regime which is implemented by fixing a permanent quota is severely limited by more basic considerations of the overall consistency of the model. Specifically, as shown in Appendix II, when $x=1 / 8 R$ equations (10) and (12) imply that the value of $8 *$ must equal

$$
B *=R_{-1} B^{*}-1 \frac{1}{R}
$$

Any permanent quota which differs from $B^{*}$ is inconsistent with equilibrium and thus cannot be sustained. Thus, when $\vec{B}^{\star} \neq B^{\star}$, the authorities can only introduce a temporary fixed quota.

\section{II.5. Unconstrained External Borrowing and the Pegged Dual Exchange Rate} Premium

In the preceding section we assumed that the government pegs the commercial exchange rate and sets a binding quota on the volume of external borrowing. The financial exchange rate and thereby the dual exchange-rate premium was allowed to be determined in the free market. In this section we consider the alternative specification of the exchange-rate policy according to which the government is assumed to peg both the commercjal and the financial exchange rates (and, thereby, it pegs the dual exchange-rate premium). With this specification the volume of external borrowing is allowed 
to be determined freely according to the private sector's preferences. As in the previous specification the present formulation of the dual exchange-rate regime also exhibits the limitations on the conduct of policies and on the viability of the dual exchange-rate regime.

In specifying this version of the regime we adopt the same assumptions as in Section II.4 concerning world prices and rate of interest, domestic output and taxes, and the comercial exchange rate. In addition we also assume that the authorities set the initial financial exchange rate at $s_{0}$ and allow for a constant percentage change thereof. Accordingly, for the period $0, \ldots, \tau$ during which the dual exchange-rate regime is in effect, the evolution of the financial exchange rate is governed by $s_{t} / s_{0}=x^{t}$. Using equations (11)-(12) the implied equilibrium value of initial wealth and the resultant volumes of (the market-determined) external borrowing, $B_{t}^{*}$, are:

$$
\begin{aligned}
& W_{0}=\frac{Y_{0}+\frac{R}{R_{0}(R-1)} Y-R_{-1} B_{-1}^{*}}{\delta^{\tau+1}+\frac{(1-\delta)}{(1-\delta x)}\left(1-(\delta x)^{\tau+1}\right)} \\
& \text { (16i) } B_{0}^{*}=R_{-1} B_{-1}^{\star}+(1-\delta) W_{0}-Y_{0} \\
& \text { (16ii) } B_{t}^{*}=R_{0} \ldots R^{t-1} R_{-1} B_{-1}^{\star}+(1-\delta) R_{0} \ldots R^{t-1} W_{0} \frac{1-(\delta x)^{t+1}}{(1-\delta x)}
\end{aligned}
$$

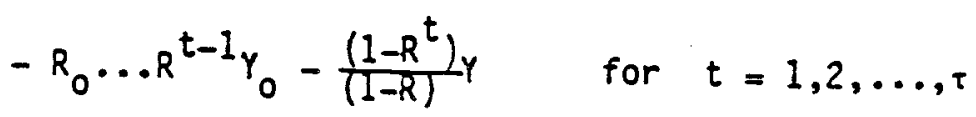

$$
\begin{aligned}
& \text { (16iii) } B_{\tau+t}^{*}=R_{0} \ldots R^{\tau+t-1} R_{-1} B_{-1}^{*}+(1-\delta) R_{0} \ldots R^{\tau+t-1} W_{0}\left[\frac{1-(\delta x)^{\tau+1}}{(1-\delta x)}+\frac{\delta^{\tau+1}}{(1-\delta)}\right] \\
& -R_{0} \ldots R^{\tau+t-1} Y_{0}-\frac{\left(1-R^{\tau+t+1}\right)}{(1-R)} Y \text { for } t=1,2, \ldots
\end{aligned}
$$


Equation (15) specifies the initial equilibrium value of private wealth. As usual the value of $w_{0}$ depends positively on current and future outputs and negatively on current and future rates of interest (which impact on the discounting of future incomes). The expression in equation (15) also illustrates the dependence of $W_{0}$ on $x$ - the constant percentage change in the premium - and on the length of the period during which the dual exchange-rate regime is in effect. As is eyident, a higher premium lowers wealth. The interpretation of this result is that the premium raises the domestic real rates of interest and thereby it lowers the present value of current and future income streams. The effect of changes in $\tau$ on the equilibrium value of initial wealth depends on whether the financial exchange rate rises or falls over time, that is, if $x$ exceeds or falls short of unity. If the financial exchange rate rises over time so that $x>1$, then lengthening the period during which the dual exchange-rate regime operates (i.e. raising $\tau$ ) results in a lower value of $W_{0}$ and vice versa. The interpretation of these results is also given in terms of the effects of $T$ on the discounting of future income streams. Accordingly, if $x$ exceeds unity, the domestic interest rates exceed world rates; therefore, under these circumstances extending $\tau$ lengthens the period during which high discount factors apply.

Equations (16) characterize the determinants of the equilibrium values of external borrowing. As seen in $(16-i)$ the current value of $B_{0}^{*}$ depends on current equilibrium wealth, on current output and on past debt comitment. A rise in $Y_{0}$ lowers external borrowing due to the usual mechanism of consumption-smoothing, whereas a rise in $w_{0}$ raises consumption and, thereby, raises external borrowing. In view of our discussion of equation (15) it is clear that a higher yalue of current and future rates of interest 
and exchange-rate premium lowers external borrowing whereas the effect of a rise in the length of the period $T$ depends on whether the financial exchange rate rises or falls over time.

Equations (16-ii) and (16-iii) show the evolution of equilibrium external borrowings for the period during which the dual exchange-rate rate operates (up to period $T$ ) as well as for the subsequent period (beyond period $\tau$ ). As seen, the value of external borrowing at period $t, B_{t}^{*}$, consists of the difference between the present values of cumulative past as well as current consumptions and the corresponding present values of outputs. This difference is adjusted for the current value of the initial debt comitment. The interest rates used in the computations of the present values are the world rates of interest. As is evident, the effect of the magnitude of the pegged premiums on $\dot{B}_{t}^{*}$ operates through its impact on the cumulative present values of past and current consumptions (the second term on the right-hand-sides of equations $(16-i i)$ and $(16-i i i))$. These effects are ambiguous since on the one hand a rise in $x$ lowers $w_{0}$ and thereby lowers consumption in all periods up to period $t$. The reduced level of consumption results in a lower value of external borrowing. On the other hand the rise in $x$ raises the domestic rate of interest and, therefore, given $W_{0}$, it induces a rise in savings from period zero up to period $t$. This rise in past savings yields higher values of current wealth and consumption and induces a rise in $B_{t}^{*}$. The net effect seems to depend on the relative magnitudes of these factors. It may be shown, however, that around an initial value of $x=1$, the effect of a rise in $x$ on the value of the external debt in the period during which the dual exchange rate regime operates is positive. Finally, the effect of extending the period of the dual exchange-rate regime on the value of the external debt operates through its impact on $W_{0}$. As 
was shown earlier, this depends on whether the dual exchange-rate premium is positive or negative. Specifically, a rise in $T$ raises $H_{0}$ and thereby raises $B_{t}^{*}$ if $x<1$ and vice versa.

In the preceding discussion we examined the effects of various changes on the value of wealth and on the evolution of external debt (and implicitly on the leyels of consumption and the current account of the balance of payments). These comparative static questions should be interpreted as reflecting the effects of temporary measures. In the long run if the dual exchange-rate regime were to last indefinitely, there would be severe constraints that limit the choice of the pegged dual exchange-rate premium. It is argued in Appendix III that a dual exchange rate regime with permanently pegged premiums cannot be sustained indefinitely unless the authorities peg the premium in a way that equates domestic and foreign real rates of interest or, alternatively, unless the authorities peg the premium in such a way so as to yield domestic rates of interest that induce zero savings. Thus, the two sustainable permanent paths of the premium are either a path along which $x=$ 1 or a path along which $x=1 / \delta R$. In the first case the evolution of the financial exchange rate yields identical real allocations as those obtained under free foreign-exchange markets. In the second case the choice of the premium el iminates the capital account of the balance of payments.

The analysis of the constraints on the long-run viability of the pegged dual exchange-rate regime also illustrates the similarities between the version discussed in section II.4 in which the authorities set a fixed quota, and the version discussed in the present section in which the authorities set the premium by fixing the percentage change in the financial exchange rate. Specifically, the case in which $x=1$ is analogous to the case in which the quota is nonbinding and the case in which $x=1 / \delta R$ is equivalent to the case 
in which the quota is set at a level which generates zero savings. ${ }^{11}$ Both versions face difficulties in sustaining long-run viability of the dual exchange-rate regime. In both cases the long run problems are induced by the ultimate futility of separating the commercial and the financial exchange markets from the forces of profit-seeking arbitrage. In addition, there are also the long-run difficulties which stem from violations of solvency constraints. Thus, the present benchmark model highlights the basic difficulties associated with the adoption of a permanent dual exchange-rate regime. III. Commercial Exchange-Rate Policies in a Model with Overlapping

The benchmark model of section II was characterized by the Ricardianequivalence property according to which for a given dual exchange-rate policy the behavior of the infinitely lived population is invariant with respect to the timing of taxes and monetary transfers. As a result of this Richardian property the level of the commercial exchange rate, $e_{0}$, played no critical role. In the present section we extend the analytical framework to a nonRicardian world.

III.1. The Overlapping Generations Model

We use a version of an overlapping-generations model in which each generation has a finite horizon. More specifically, in order to obtain simple aggregate behavior we adopt Blanchard's (1985) formulation by which output per capita is fixed and each individual's probability of survival between two consecutive periods is $\gamma(0<\gamma \leq 1)$ which is assumed to be independent of age. The size of each cohort at birth is normalized to unity and, therefore, 
its size at age $a$ is $r^{a}$. The size of the population is the sum of all the sizes of all cohorts. Thus the (fixed) population size is $\sum_{a=0}^{\infty} \gamma^{a}=1 / 1-\gamma$.

The risk-free rate of interest is given by the world at the level $r$, where $r=R-1$. The rate of interest that governs the behavior of individuals takes into account the risk associated with mortality. Competition in capital markets implies that the individual risk premium is set at the actuarially-fair level and, therefore, the risk-adjusted interest rate is $(R / Y)-1.12$

In order to incorporate these considerations into the structure of the benchmark model we start with the specification of the individual and then aggregate the quantities that are applicable to each individual into those of the aggregate private sector. Analogously to equation (1) the typical budget constraint faced by an individual of age a at time $t$ is

(17) $e_{t} p_{t}^{*} c_{a, t}=e_{t-1} p_{t-1}^{*} y_{t-1}-T_{t}-R / r s_{t} b_{a-1, t-1}$

where $c_{a, t}$ and $b_{a, t}$ denote, respectively, the level of consumption and the size of debt of an individual of age a at time $t, y_{t}$ denotes per-capita output. Consolidation of the periodic budget constraints yields equation (18) as the size of wealth, $w_{a, 0}$, of an individual of age a at period $t=0$.

$$
W_{a, 0}=\frac{M}{e_{0} p_{0}^{\star}}-\frac{s_{0}}{e_{0} p_{0}}\left[\sum_{t=0}^{\infty}\left(\frac{Y}{R}\right)^{t} \frac{T_{t}}{s_{t}}+\sum_{t=0}^{\infty}\left(\frac{r}{R}\right)^{t e_{t-1} p_{t-1}^{\star}} y_{t-1}-\frac{R-1}{r} b_{a-1,-1}\right] .
$$

The budget constraints require that the discounted sum of consumption equals the value of wealth so that

$$
\frac{s_{0}}{e_{0} p_{0}} \sum_{t=0}^{\infty}\left(\frac{r}{R}\right)^{t} C_{a, t}=w_{a, 0} .
$$


As is evident from the definition of wealth, the discounting is performed with the aid of the risk-adjusted discount factor $r / R$. This should be constructed with the formulation in equation (2) of the benchmark model in which the discount factor used by the private sector was the world risk-free discount factor $1 / R$.

The equilibrium value of wealth $W_{a, o}$ is computed in an analogous manner to that in section II by taking into account the government foreign exchange interventions (equation (5)), the money market clearing condition (9), and noting that the monetary injections induced by foreign exchange interventions which accrue to the cohort of age a are

$$
X_{t}=-e_{t}\left(B_{t}^{*}-R B_{t-1}^{\star}\right)+s_{t}\left(B_{t}-R B_{t-1}\right)
$$

Following a similar procedure outlined in Appendix I the equilibrium wealth of an individual of age a at period $t=0$ is

$$
\begin{aligned}
W_{a, 0}=\frac{s_{0}}{e_{0} p_{0}^{*}}\left(\sum_{t=0}^{\infty}\left(\frac{r}{R}\right)^{t} \frac{e_{t} p_{t}^{*}}{s_{t}} y_{t}\right. & +\sum_{t=0}^{\infty}\left(\frac{r}{R}\right)^{t}\left(\frac{e_{t}}{s_{t}}-\frac{e_{t+1}}{r s_{t+1}}\right) B_{a+t, t}^{\star} \frac{e_{O_{R}}}{s_{0}}-B^{*}-1 \\
& -(1-r) \sum_{t=0}^{\infty}\left(\frac{r}{R}\right)^{t} B_{t}+R_{-1} B_{-1}-\frac{R_{-1}}{r} b_{a-1,1} .
\end{aligned}
$$

Recalling that the size of the population is $1 /(1-\gamma)$, the aggregate equilibrium wealth per-capita, $W_{0}$, is obtained by using the definition $W_{0}=(1-\gamma) \sum_{a=0^{\gamma}}^{\infty} W_{a, 0^{\circ}}$. Thus,

$$
\begin{aligned}
& W_{0}=\frac{s_{0}}{e_{0} p_{0}^{t}}\left(\sum_{t=0}^{*}\left(\frac{\gamma}{R}\right) \frac{t e_{t} p_{t}^{*}}{s_{t}} y_{t}+\left[\left(\frac{\gamma}{R}\right)^{t}\left(\frac{e_{t}}{s_{t}}-\frac{e_{t+1}}{s_{t+1}}\right) B_{t}^{\star}-\frac{e_{0}}{s_{0}} R_{-1} B_{-1}^{\star}\right.\right. \\
& \left.-(1-\gamma) \sum_{t=0}^{\infty}\left(\frac{\gamma}{R}\right)^{t} B_{t}\right\} .
\end{aligned}
$$


Equation (20) specifies the equilibrium value of per-capita wealth at period $t=0$. It is the analogue to equation (10) of the benchmark model. As may be seen, the two expressions coincide in the special case of $r=1$. In general the role of the finite horizon is manifested through three channels. First, as indicated earlier, the discounting of future flows is performed by using the risk adjusted discount factor $r / R$. Second, the value of $Y$ together with the dual exchange rate policy determine the impact of the difference between the domestic private real rate of interest and the corresponding world safe rate on the equilibrium value of initial wealth. As in the benchmark model $\left[e_{t} / s_{t}-e_{t+1} / s_{t+1}\right]$ measures the distortion. In the present case, however, the discounting is done by using the risk-adjusted discount factor. Third, the value of $r$ determines the effect of changes in government debt (associated with interventions in the financial exchange rate) on private wealth. This channel is represented by the last term on the right-hand-side of equation (20). In the extreme case of infinite horizon (with $\gamma=1$ ) the last term vanishes and the Ricardian proposition reemerges. With a finite horizon, (with $\gamma<1$ ) changes in government debt that are induced by interventions in the financial exchange rate induce changes in private-sector's net wealth. These changes in wealth arise from the fact that the private sector discounts the future flows of taxes by using the risk-adjusted discount factor $Y / R$ whereas the government uses the risk-free world discount factor, $1 / R$. In the special case for which there is no intervention in the financial exchange rate, $e_{t}=s_{t}$ (since $\frac{e_{t}}{s_{t}} B_{t}^{*}=B_{t}$ ). In that case equation (20) coincides with (10'). Finally we note that all the terms on the right-hand-side of (20) except for the last term depend on the relation between the relative evolutions of the commercial and the financial exchange rates, $e_{t} / e_{0}$ and $s_{t} / s_{0}$ but not on the initial difference between the levels of the two exchange rates. On the other hand the last term on the righthand-side of (20) depends on the initial value of $s_{0} / e_{0}$. For a positive debt 
a rise in $s_{0} / e_{0}$ raises indebtedness and lowers wealth. This dependence on the level of the exchange rate reflects the departure from the Ricardian equivalence and indeed when $\gamma=1$, the last term vanishes, the equilibrium value of initial wealth does not depend on the levels of the initial exchange rates and the Ricardian proposition reemerges.

Finally, since in our dual exchange rate regime, without fiscal policies, $\left(e_{t} / s_{t}\right) B_{t}^{*}=B_{t}$, equation $(20)$ can be simplified to

$$
W_{0}=\frac{s_{0}}{e_{0} p_{0}^{*}}\left[\left[\sum_{t=0}^{\infty}\left(\frac{\gamma}{R}\right)^{t} \frac{e_{t} p_{t}^{*}}{s_{t}} y_{t}+r\left[\sum_{t=0}^{\infty}\left(\frac{\gamma}{R}\right)^{t}\left(\frac{e_{t}}{s_{t}}-\frac{e_{t+1}}{s_{t+1}}\right) B_{t}^{*}-\frac{e_{0}}{s_{0}-1} B_{-1}^{*}\right]\right.\right.
$$

III.2. Devaluation and the Timing of Monetary Injections

In this section we examine the effects of commercial exchange-rate policies on the exchange-rate premium. Obviously these effects depend crucially on the timing of the monetary injections that are associated with the management of the two exchange rates. In order to sharpen the analysis we assume that the monetary policy is not perfectly coordinated to offset changes in the pegged commercial exchange rate. With perfect coordination devaluations affect only nominal magnitudes without any impact on the real equilibrium of the system. 13

Consider a stylized, example, with stationary outputs, in which the commercial exchange rate is raised at time $t=0$ from its previous unitary level to $e$ and the new rate is then mantained throughout the entire future. The change in the current level of wealth is given by (22) $\Delta W_{0}=\frac{1-e}{e} g-\frac{\Delta T_{0}}{e}-\frac{\gamma}{(R-\gamma)} \frac{\Delta T}{e}$.

The first term on the right hand side of equation (22) represents the capital gains that are associated with the revaluation of the money stock- the propotional decline in prices, (1-e)/e, times the real value of money, $y$. The second and the third terms on the right hand side of equation (22) represent the implied change in monetary absorption (taxes) 
in the present, $\Delta T_{0}$, and in the entire future $\Delta T$, where $(\gamma /(R-\gamma)$ is the discounted sum of one-dollar stream commencing in period $t=1$, evaluated with the effective discount factor $(Y / R)$. The tax change is required in order to preserve solvency of the government budget in the face of the decline in foreign exchange reserves by the amount $[(1-e) / e] y-\Delta T_{0} / e$. This decline equals the fall in demand for domestic money minus money withdrawls through taxes. The government budget constraint yields:

$$
\frac{e-1}{e} y+\frac{\Delta T_{0}}{e}+\frac{\Delta T}{e} \frac{1}{(R-1)}=0
$$

where $1 /(R-1)$ is the discounted sum of a one-dollar stream commencing in period $t=1$, evaluated with the market discount factor $1 / R$. Equation (23) indicates that in the absence of initial government debt and government spending, the sum of the present values of explicit taxes ( $T_{0}$ and $T$ ) and inflationary taxes $[(e-1) / e] y$ must be zero. From equation (23) we can solve for the change in future taxes $\frac{\Delta T}{e}=(R-1)\left[\frac{(1-e)}{e} y-\frac{\Delta T_{0}}{e}\right]$. Substituting this expression into equation (22) yields:

(24) $\Delta W_{0}=(1-Y) \frac{R}{(R-\gamma)}\left[\frac{(1-e)}{e} y-\frac{\Delta T_{0}}{e}\right]$.

It is worth noting that when $y=1$, equation (24) implies that $\Delta W_{0}=0$; that is, devaluations have no real effects.

For simplicity assume now that the transitory quota on external borrowing is in effect only in the first two periods, $t=0,1$. Using equations (21) and (24) yields:

(25)

$$
\begin{aligned}
& W_{0}=\left[1+\frac{\gamma}{x(R-Y)}\right] y+(1-Y) \frac{R}{(R-\gamma)}\left[\left(\frac{1-e}{e}\right) y-\frac{\Delta T_{0}}{e}\right] \\
& +\gamma\left[\frac{x-1}{x}\right] \bar{B}^{*}-R_{-1} B_{-1}^{*}, \text { where } x=s_{1} / s_{0} .
\end{aligned}
$$


Onder the assumption that the utility function is logarithmic and that the subjective discount factor, $\delta$, is constant it can be shown that the aggregate consumption function (which is derived from individuals' maximization of expected utility) is $c_{0}=(1-\gamma \delta) \mathrm{W}_{0}$. Using this function and the familiar relationship of national accounts we derive $B_{0}^{*}=\bar{B}^{*}$, (26) $\vec{B} *=(1-Y \delta) W_{0}+R_{-1}^{B *}-g$.

For a given level of quota on external borrowing, $\bar{B}^{-}$, equations (25)(26) yield a solution for the percentage future change in the financial exchange rate (from period 0 to period 1 ). The rise in the commercial exchange rate in period 0 impacts negatively on the level of wealth and on the evolution of the financial exchange rate over time. This is seen by differentiating equations (25)-(26) which yields ${ }^{14}$$$
\frac{d W_{0}}{d e}=-(1-\gamma)\left(\frac{R}{R-Y}\right) \frac{y}{e^{2}}<0
$$$$
\text { (28) }\left(\frac{e}{x}\right) \frac{d x}{d e}=\frac{(1-\gamma) \frac{x R}{(R-y)}\left(\frac{y}{e}\right)}{\left(\bar{B}^{*}-\frac{y}{(\bar{R}-\gamma)}\right)}<0 .
$$

It is noteworthy, again, that in the special case in which $\gamma=1$ the devaluation has no effect on the evolution of the exchange rate premium over time. Since the effective real discount rate equals $\mathrm{Rx} / \gamma$ the devaluation lowers the effective real interest rate. Substituting equations (24)-(25) in the aggregate analogue of equation (18) yields:

(29) $W_{0}=\frac{M-T_{0}}{e}+\frac{\gamma}{x(R-Y)}(Y-T)+(I-Y)\left(\frac{R}{R-\gamma}\right)\left[\left(\frac{1-e}{e}\right) y-\frac{\Delta T_{0}}{e}\right]-\frac{s_{0}}{e} R_{-1} B_{-1}^{*} \cdot$ Equation (29) expresses current wealth in terms of the real value of the stock of money in the beginning of perlod o plus the present value of the output stream (note that the nominal proceeds from sales of output are distributed with one period lag, requiring discounting to the present by 
the factor $\gamma(x R)$, minus the present value of taxes, plus the capital gains arising from the devaluation, and winus the inftial debt obligation.

Given the quota on external borrowing, $\bar{B}^{\star}$, the new comercial exchange rate, $e$, and period zero tax changes, $\Delta T_{o}$, (which yield the solution for $x$ and $w_{0}$ from equations $(25)-(26)$ ), equation (28) can be solved for $s_{0}$ and the implied exchange rate premilum. To evaluate the effect of the devaluation (with no change in current monetary injections) on the exchange rate premium, we differentiate equation (29), and using (27)-(28), gields :

(30) $\left(\frac{e}{s_{0}}\right)\left(\frac{d s_{0}}{d e}\right)=1-\frac{\left(M-T_{0}\right) / e}{s_{0}^{R}-1_{-1}^{B^{*}}}+\frac{(1-\gamma)}{s_{0} R_{-1} B_{-1}^{\star}}\left[\left(\frac{R}{R-\gamma}\right) \frac{\Delta T_{0}}{e}+\frac{R y(g-T)}{(R-Y)\left(y-(R-Y) \bar{B}^{*}\right)}\right]$.

As can be seen from equation (30) with a positive initial external debt the rise in the commercial exchange rate does not, in general, lead to a proportional increase in the free financial exchange rate. The fall in the real value of the initial stock of money taken by itself leads to a decline in the financial exchange rate whereas the effect of the devaluation on the effective real interest rate, taken by itself, raises the financial exchange rate. When the initial stock of money (relative to output) is small the financial exchange rate overshoots and the exchange rate premium rises and vice versa.

In this section we have analysed the circumstances under which changes in the levels of the commercial exchange rate and of the nominal money stock influence the real equilibrium. We focused on the effects of these policies on the real value of initial private sector debt commitment, the real value of wealth, the effective real interest rate and the intergenerational distribution of welfare. The real effects of such policies (that is, the departure from the Ricardian equivalence) stem from the "myopic" element in 
private sector behavior reflecting the finiteness of life. ${ }^{15}$ These issues of the neutrality of money supply and of exchange rate policies carry over to a more elaborate framework in which the economy produces tradable and nontradable goods. In that case the nominal exchange rate regime is not neutral in its effect on the real exchange rate and changes in the money stock and in the nominal exchange rate impact on the real exchange rate. ${ }^{16}$

\section{Concluding Remarks}

This paper introduced critical intertemporal considerations into the analysis of dual exchange-rate systems. These intertemporal considerations cast serious doubts on the long-run viability of such exchange-rate regimes. Specifically, we have examined in detail the restrictions that solvency requirements on both the private and the public sectors impose on the admissible set of policies.

Even though dual exchange rate regimes may not be viable in the long run, they can be substained in the short run. In this context we have specified the nature of the distortions introduced by the adoption of different exchange rates for commercial and for financial transactions and we have examined the implications of the regime for the intertemporal distribution of effective taxes and for the intergenerational distribution of welfare.

Our model has been characterized by forward looking individuals who take full account of current and prospective government policies. We have used the model in order to specify the precise mechanisms and monetary changes associated with the dual exchange-rate policies. In so doing we have provided an analytical framework that facilitates the identification and clarification of the mechanisms governing the operation of dual exchange rate systems. 
While we have focused on the limited viability of dual exchange rate regimes, our analysis is also applicable for the ongoing discussion of the sequencing of economic liberalization policies. One of the key questions addressed in that discussion concerned the consequences of a removal of restrictions on current-account and on capital-account transactions. In particular, a debated issue has been the proper order in which such restrictions ought to be removed. 17 Our analysis of the operation of the system under a binding quota on external borrowing has implications for that debate. 


\section{APPENOIX}

1. The equilibrium Value of $W_{0}$

In order to compute the equilibrium value of initial wealth, $W_{0}$, we first rewrite equation (2) of the text as

$$
\begin{aligned}
\sum_{t=0}^{\infty} \frac{e_{t} p_{t}^{*}}{s_{t}} d_{t} c_{t}= & \frac{M-T_{0}}{e_{0} p_{0}^{*}}+\sum_{t=0}^{\infty} d_{t} \frac{e_{t-1} p_{t-1}^{*}}{s_{t}} y_{t-1}- \\
& \sum_{t-1}^{\infty} d_{t} \frac{T_{t}}{s_{t}}-\frac{s_{0}}{e_{0} p_{0}^{*}} R_{-1} B_{-1} \equiv W_{0} .
\end{aligned}
$$

where $d_{t}=\frac{s_{0}}{e_{0} p_{0}^{t}} \frac{1}{R_{0} R_{1} \ldots R_{t-1}}$

Next, we note that from equation (6) in the text

$$
M_{t-1}-T_{t}=M_{t}-x_{t}
$$

Using the money market equilibrium condition (9) we replace $e_{t-1} p_{t-1}^{\star} Y_{t-1}$ by $M_{t-1}$ and, using (I.2) in (I.1) yields

$$
w_{0}=\frac{M_{0}-x_{0}}{s_{0}}+d_{1} \frac{M_{1}-x_{1}}{s_{1}}+\ldots+d_{t} \frac{M_{t}-x_{t}}{s_{t}}+\ldots-\frac{s_{0}}{e_{0} p_{0}^{*}} R_{-1}^{B}-1
$$

Substituting $e_{t} p_{t}^{*} Y_{t}$ for $M_{t}$ yieids

$$
W_{0}=\sum_{t=0}^{\infty} \frac{e_{t} p_{t}^{*}}{s_{t}} Y_{t}-\sum_{t=0}^{\infty} d_{t} \frac{X_{t}}{s_{t}}-\frac{s_{0}}{e_{0} p_{0}^{*}} R_{-1}^{B}-1
$$


Equation (I.4) shows that the equilibrium value of $W_{0}$ depends on $x_{t}$, which, in turn, reflects the precise specification of the dual exchange-rate regime. In order to obtain further insights we substitute equation (5) of the text for $x_{t}$. Accordingly the term

$-I_{t=0}^{\infty} \delta_{t} \frac{x_{t}}{s_{t}}$ can be written as:

$$
-\sum_{t=0}^{\infty} d_{t} \frac{x_{t}}{s_{t}}=-\sum_{t=0}^{\infty} d_{t} \frac{e_{t} p_{t}^{*}\left(Y_{t}-c_{t}\right)+s_{t}\left(B_{t}-R_{t-1} B_{t-1}\right)}{s_{t}}
$$

Substituting equation ( 7$)$ for $p_{t}^{\star}\left(Y_{t}-C_{t}\right)$ yields

$$
\begin{aligned}
& -\sum_{t=0}^{\infty} d_{t} \frac{x_{t}}{s_{t}}=\frac{s_{0}}{e_{0} p_{0}^{*}}\left[\frac{e_{0}}{s_{0}}\left(B_{0}^{*}-R_{-1} B_{-1}^{*}\right)+\frac{e_{1}}{s_{1}} \frac{1}{R_{0}}\left(B_{1}^{*}-R_{0} B_{0}^{*}\right)+\ldots\right]- \\
& \frac{s_{0}}{e_{0} p_{0}^{*}}\left[\left(B_{0}-R_{-1} B_{-1}\right)+\frac{1}{R_{0}}\left(B_{1}-R_{0} B_{0}\right)+\ldots\right]= \\
& \frac{s_{0}}{e_{0} p_{0}^{*}}\left[\left(\frac{e_{0}}{s_{0}}-\frac{e_{1}}{s_{1}}\right) B_{0}^{*}+\frac{1}{R_{0}}\left(\frac{e_{1}}{s_{1}}-\frac{e_{2}}{s_{2}}\right) B_{1}^{*}+\ldots\right]-\frac{1}{p_{0}^{*} R_{-1}} B_{-1}^{*}+\frac{s_{0}}{e_{0} p^{*}}-1 B^{B}-
\end{aligned}
$$

Subsituting (I.5) into (I.4) yields equation (10) of the text.

II. The Equilibrium Dual Exchange-Rate Premium

In this part of the appendix we derive the expressions releyant for the analysis of the equilibrium dual exchange rate premium for the case in which the authorities peg the commercial exchange rate and set a quota for $\tau$ on the volume of external debt ${\overline{\sigma_{t}}}_{t}$. We assume that from period $r+1$ onwards the quota is relaxed and the financial exchange rate is unified with the pegged commercial exchange rate. In order to gain insight we specialize the analysis to the case in which the policy is stationary in the sense that 
$B_{t}^{*}=\vec{B}^{*}$ and $e_{t}=e=1$. We further focus on the equilibrium in which the world price and rate of interest are stationary, that is $p_{t}^{*}=p^{\star}=1$ In order to be able to analyze the effect of a once and for all change in the paths of output and world interest rates, we distinguish between the current interest rate and output, represented by $R_{0}$ and $Y_{0}$, and their corresponding future stationary values $R$ and $Y$.

Substituting these assumptions into equation (11), denoting the term $s_{t} / s_{0}$ by $x_{t}$, yields

$$
\text { (a) } \vec{B}^{t}=(1-\delta) W_{0}-Y_{0}+R_{-1} \vec{B}_{-1}^{t}, \text { for } t=0
$$

$$
\begin{aligned}
& \vec{B}^{*}=(1-\delta) R_{0} R^{t-1_{W}}\left(1+\delta x_{1}+\delta^{2} x_{2}+\ldots+\delta x_{t}\right) \\
& -\left[R_{0} R^{t} Y_{0}+\left(R^{t-1}+\ldots+R+1\right) Y\right]+R_{0} R^{t-1} R-\bar{B}_{-1}^{*} \text {, for } t=1, \ldots, \tau \text {. }
\end{aligned}
$$

From $(I I-I)-(a)$ the initial equilibrium value of $W_{0}$ is

(II-2) $\quad W_{0}=\frac{\bar{B}^{*}-R_{-1} \bar{B}^{\star}-1+Y_{0}-R_{-1} B *-1}{1-\delta}$

From $(I I-1)-(b)$ together with $(I I-2)$ we can solve for the value of $x_{t}=s_{t} / s_{0}$ during the $r$ periods for which the quota is in effect. Thus,

$$
\frac{s_{t}}{s_{0}}=\frac{Y-(R-1) \vec{B}}{(1-\delta) R_{0} W_{0}} \frac{1}{R^{t-1} \delta_{\delta} t} \quad \text { for } t=1, \ldots, T \text {. }
$$

Equation (II-3) specifies the evolution of the financial exchange rate. finally, in order to determine the initial equilibrium value of the financial 
exchange rate we substitute equations (II-2) and (II-3) into equation (2) of the text noting that for the periods $\tau+1, \ldots, \infty, s_{t}=e_{t}=1$, and assuming stationary lump-sum taxes, $T$, for periods $t=1, \ldots$, yields

$$
\begin{aligned}
s_{0}=\left[\frac{1}{R_{-1} B_{-1}^{*}}\right]\left[-\frac{\left(\frac{R}{R-1}\right) Y-R_{-1} B_{-1}^{*}}{(1-\delta)\left(A\left(\frac{R}{R-1}\right)\left(1-R^{-\tau-1}\right)+\frac{\delta^{\tau+1}}{T-\delta}\right)}\right. \\
\left.+(Y-T)\left(\frac{1-\delta^{\tau+1}}{(1-\delta) A}+\frac{R}{(R-1) R^{\tau+2}}\right)+M-T_{0}\right]
\end{aligned}
$$

where

$$
A=\frac{Y-(R-1) \overline{B^{\star}}}{Y_{0}-R_{-1} B_{-1}^{\star}+\bar{B}^{\star}}
$$

111. The Constraints on the Choice of the Pegged Exchange-Rate Premtum

In this part of the appendix we compute the values of the pegged exchange-rate premium that are consistent with the maintenance of an indefinite dual exchange rate regime. The solvency constraint requires that at the limit, the discounted value of external debt must be zero, mamely, $\lim _{t \rightarrow \infty}\left(R_{0} \ldots R_{t-1}\right)^{-1} B_{t}^{*}=R_{-1} 8_{-1}^{\star}+(1-\delta) W_{0} \lim _{t \rightarrow \infty} \frac{1-(\delta x)^{t+1}}{1-\delta x}-y_{0}-\frac{R}{R_{0}} \frac{Y}{R-1}=0$.

In the case for which $x=1$ the value of $W_{0}$ is given by equation (10') of the text. Substituting (10') into the above solvency constraint and assuming that outputs prices and the rates of interest are stationary, reveals that the constraint is satisfied. In that case the domestic real rates of interest equal the world levels. 
Another feasible path for the exchange rate premium can be obtained by inducing an equality between income and spending. Under such circumstances the current account of the balance-of-payments is balanced and the value of the external debt remains stationary. With a fixed $B_{t}^{*}$ it is eyident that the solvency constraint is satisfied. Finally, in order to induce such an equality between spending and income (with stationary outputs, prices and rates of interest) equation (4) in the text implies that $x$ must equal $1 / \delta R$.

In order to compare the fixed quota $\bar{B}^{*}$ which results in a value of $x$ that is equal to $(1 / \delta R)$ we substitute (1/SR) for $x$ into equation (10) in the text and obtain

$$
\begin{aligned}
W_{0} & =Y\left(1+\delta+\delta^{2}+\ldots\right)-R_{-1} B_{-1}^{*}+(1-\delta R)\left[1+\frac{1}{R}+\left(\frac{1}{R}\right)^{2}+\ldots\right] B^{*} \\
& =\frac{Y}{1-\delta}-R_{-1} B_{-1}^{*}+\frac{(1-\delta R) B^{*}}{(1-\delta)}
\end{aligned}
$$

On the other hand equation (12) implies that for $x=1 / 8 R$

$$
W_{0}=\frac{Y}{1-\delta}-\left(\frac{R-1}{R}\right) \frac{R-1^{*}-1}{(1-\delta)} \text {. }
$$

These two equations for $W_{0}$ imply that

$$
B^{*}=\frac{R}{R} B_{-1}^{*}
$$

Note that in the present case with $\delta R<1,8^{*}>0$.

Finally it can be shown that any constant value of the dual exchange-rate premium other than $x=1$ or $x=1 / \delta R$, results in an inconsistency among equations (10), (16ii) and the solvency requirement. 
FOOTNOTES

1 For a recent analysis see Dornsusch (1985) and for a survey see Lanyi (1975).

${ }^{2}$ For an analysis of aspects of the relations between taxes on capital flows, quantitative controls and dual exchange rates see Adams and Greenwood (1985), Greenwood and Kimbrough (1984), Liviatan (1981), and Stockman and Hernandes (1985). For a related analysis of the insulation properties of twotier exchange-rate systems see Argy and Porter (1972), Fleming (1971), Flood and Marion (1982), Marion (1981) and Swoboda (1974).

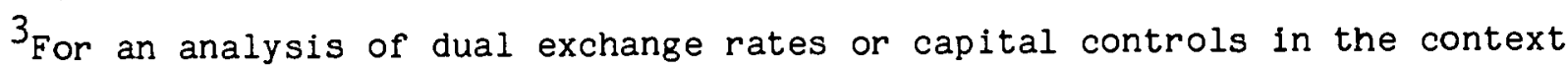
of public finance and distortionary taxes see Aizenman (1986) and Persson and Svensson (1985) and for an analysis of dual exchange rates as a second-best policy see Adams and Greenwood (1985), Basevi (1985) and Flood and Marion (1982).

${ }^{4}$ Among the numerous studies dealing with these issues are Aizenman (1985), Cumby (1984), de Macedo (1982), Dornbusch (1976, 1985), Flood (1978), Guidotti (1985), Lizondo (1984), Mussa (1986), Obstfeld (1984) and van Wijnbergen (1985).

${ }^{5}$ The fact that in general a dual exchange-rate regime is not viable in the long run implies that a steady-state analysis of such a regime may not be meaningful. Therefore, great care should be given to steady-state results that are based on descriptive models which are not constrained by intertemporal solvency requirements. 
6 For an analysis of the effects of departures from a complete segmentation between the commercial and financial exchange markets see Bhandari and Decaluwe (1984).

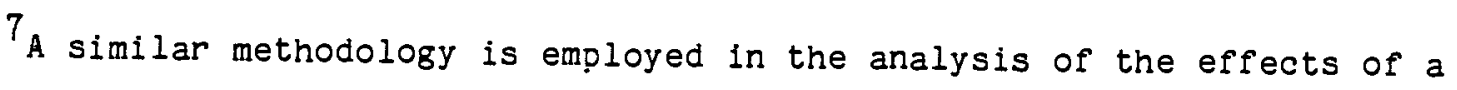
devaluation from an initial position of balance of payments equilibrium, and in the analysis of the effects of a tariff or a quota in a small competitive (price taking) open economy. In both cases the model itself does not provide a rationale for the policy but the analysis yields insights into the pure effects of such policies.

${ }^{8}$ The solvency condition is $\lim _{t \rightarrow \infty} \frac{e_{0}}{e_{t}} \frac{s_{0}}{s_{t}} \frac{1}{R_{0} R_{1}, \ldots, R_{t}} B_{t}=0$.

${ }^{9}$ The present specification presumes that the exchange rate applicable to debt-service payments is the financial exchange rate, s. Alternatively, we could have assumed (following some conventions) that the exchange rate applicable to debt-service payments is the commercial exchange rate. In that case, a typical equation in (1) would be

$$
e_{t} p^{*} C_{t}=e_{t-1} p_{t}^{*} Y_{t-1}-T_{t}-s_{t} B_{t}-e_{t}\left(R_{t-1}-1\right) B_{t-1}-s_{t} B_{t-1} \text {. }
$$

In that case the intertemporal price of $C_{t}$ (the relative price of consumption in two consecutive periods $)$ is $\left[\left(s_{t} e_{t-1}\right) / e_{t}\left(R_{t-1}-1\right)+s_{t}\right] /\left[s_{t-1} e_{t} / s_{t} e_{t-1}\right]$. In that case the domestic rate of interest equals the foreign rate if $e_{t}=s_{t}=s_{t-1}$. The key results of our analysis do not depend on this specification.

${ }^{10}$ The solvency requirement specifies that at the limit the discounted value of external debt is zero; hence $\lim _{t \rightarrow \infty}\left(R_{0} \cdots R_{t-1}\right)^{-1} B_{t}^{*}=0$. For further reference we note that $R_{-1} B_{-1}^{*} / p_{0}^{*}$ in equation ( 8 ) can also be viewed as summarizing the path of current and future government spending. Specifically, a rise in government spending entails, in present value terms, a higher value of initial debt. Therefore, this formulation is also useful for the analysis of the effects of fiscal policies. 
${ }^{11}$ The real allocations induced by a policy which pegs the value of $x$ at a level $1 / \delta R$ will be identical to those obtained by fixing a permanent quota $\bar{B}^{*}$ at a level $\bar{B}^{*}=R_{-1} B_{-1}^{*} \frac{1}{R}$ as shown in Appendix III.

12 For a detailed description of such a model see Blanchard (1985) and Frenkel and Razin (1984, 1986). For a Monetary model which uses a similar framework see Helpman and Razin (1985).

${ }^{13}$ The subsequent discussion draws on Helpman and Razin (1985). We assume that the devaluation of the currency does not result in real revaluation of private debt, or alternatively, that if there are capital gains on existing debt they are taxed away immediately.

14 Note that private sector's solvency condition implies that the external debt, $R E^{*}$, must be smaller than the present value of labor income $R y /(R-\gamma)$. ${ }^{15}$ It is relevant to note, however, that in principle these real effects can be avoided by adopting a specific course of monetary policy designed to offset capital gains and losses on existing assets.

${ }^{16}$ For a thorough analysis of the lack of neutrality of the nominal exchange rate regime in its relation to the real exchange rate see Mussa (1985). 17 For an analysis of these issues see Frenkel (1982, 1983), Edwards (1985), Khan and Zhaller (1983) and McKinnon (1982). 
REFERENCES

Adams, Charles and Jeremy Greenwood, "Dual Exchange Rate Systems and Capital Controls: An Investigation", Journal of International Economics 18, (February 1985): 43-63.

Aizenman, Joshua, "Adjustment to Monetary Policy and Devaluation Under TwoTier Fixed Exchange Rate Regimes", Journal of Development Economics 18 (1985): $\quad 153-69$.

- On the Complementarity of Commercial Policy, Capital

Controls and Inflation Tax", Canadian Journal of Economies 19, (February 1986).

Argy, Victor and Michael G. Porter, "The Forward Exchange Market and the Effects of Domestic and Foreign Disturbances Under Alternative ExchangeRate Regimes", IMF Staff Papers 19, (November 1972): 503-28.

Basevi, Giorgio, "Instruments for Preserving Economic Efficiency and International Capital Mobility" in Capital Controls and Foreign Exchange Legislation, Euromobiliare, Occasional Paper, Milano, (June 1985). Bhandari, Jagdeep $S$. and Bernard Decaluwe, "Stochastic Implications of Incomplete Separation Between Commercial and Financial Exchange Markets" unpublished manuscript, (June 1984).

Blanchard, Olivier J., "Debt, Deficits and Finite Horizons", Journal of Political Economy 93, (April 1985): 223-47.

Cumby, Robert E., "Monetary Policy Under Dual Exchange Rates", Journal of International Money and Finance 3, (August 1984): 195-208. 
Dornbusch, Rudiger, "The Theory of Flexible Exchange Rate Regimes and Macroeconomic Policy", Scandinavian Journal of Economics 78, No. 2 (May 1976): $255-75$.

, "Special Exchange Rates for Capital Account Transactions"

NBER Working Paper Series No. 1659, (July 1985).

Edwards, Sebastian, "The Order of Liberalization of the External Sector in Developing Countries," Essays in International Finance, International Finance Section, Princeton University, No. 161, December 1985. Fleming, J. Marcus, "Dual Exchange Markets and Other Remedies for Disruptive Capital Flows", IMF Staff Papers 21, (March 1971): 1-27.

Flood, Robert P., "Exchange Rate Expectations in Dual Exchange Markets", Journal of International Economics 8, (February 1978): 65-78. and Nancy P. Marion, The Transmission of Disturbances Under Alternative Exchange-Rate Regimes with Optimal Indexation", Quarterly Journal of Economics 97, (February 1982): 43-66.

Frenkel, Jacob A., "The Order of Economic Liberalization: Lessons from Chile and Argentina: A Comment" in K. Brunner and A.H. Meltzer (eds.), Economic Policy in a Changing World Vol. 17 of the Carnegie-Rochester Conference Series on Public Policy, Amsterdam, North-Holland, 1982. , "Economic Liberalization and Stabilization Programs" in N. Ardito Barletta, M. Blejer and L. Landau (eds.), Economic Liberalization and Stabilization Policies in Argentina, Chile, and Uruguay: Applications of the Monetary Approach to the Balance of Payments, Washington, D.C.: The World Bank, 1983. and Assaf Razin, "Budget Deficits and Rates of Interest in the World Economy", NBER Working Paper Series, No. 1354, (May 1984). , Fiscal Policies in the World Economy", Journal of Political Economy 94 , No. 2, (June 1986). 
Greenwood, Jeremy and Kent Kimbrough, "An Investigation in the Theory of Foreign Exchange Controls", Centre for the Study of International Economic Relations, University of Western Ontario, Working Paper No. 8431, August 1984.

Guidotti, Pablo E., A study on Dual Exchange Rates, Unpublished Ph.D. Dissertation, University of Chicago, (July 1985).

Helpman, Elhanan, "An Exploration in the Theory of Exchange Rate Regimes", Journal of Political Economy, 89, (October 1981): 865-90. and Assaf Razin, "Dynamies of a Floating Exchange Rate System", Journal of Political Economy 90, (August 1982): 728-54.

, "Exchange Rate Management: Intertemporal Tradeoffs", NBER Working Paper Series, No. 1590, (March 1985).

Khan, Mohsin S. and Roberto Zahller, "The Macoreconomic Effects of Changes in Barriers to Trade and Capital Flows: A Simulation Analysis," IMF Staff Papers 30, No. 2 (June 1983): 223-82.

Lanyi, Anthony, "Separate Exchange Markets for Capital and Current Transactions", IMF Staff Papers 22, (November 1975): 714-49. Liviatan, Nissan, "Neutral Monetary Policy and the Capital Import Tax", unpublished manuscript, The Hebrew University, 1979.

Lizondo, Jose, "Exchange Rate Differentials and Balance of Payments Under Dual Exchange Markets", unpublished manuscript, IMF, 1984.

Lucas, Jr. Robert E., "Interest Rates and Currency Prices in a Two-Country World", Journal of Monetary Economics 10, (November 1982): 335-60. de Macedo, Jorge B., "Exchange Rate Behavior with Currency Inconvertibility", Journal of International Economics 12, (February 1982): 65-81. Marion, Nancy P., "Insulation Properties of a Two-Tier Exchange Market in a Portfolio Balance Model", Economica 48, (1981): 61-70. 
McKinnon, Ronald I., "The Order of Economic Liberalization: Lessons from Chile and Argentina" in K. Brunner and A.H. Meltzer (eds.), Economic Policy in a Changing World, Vol. 17 of the Carnegle-Rochester Conference Series on Public Policy, Amsterdam: North-Holland, 1982.

Mussa, Michael, "Nominal Exchange Rate Regimes and the Behavior of Real Exchange Rates: Evidence and Implications," Presented at the CarnegieRochester Conference on Public Policy, Carnegie-Mellon University, November 1985.

- "The Real Exchange Rate as a Tool of Commercial Polfcy" in

Edwards, Sebastian and Liaquat Ahamed (eds.) Economic Adjustment and Exchange Rates in Developing Countries, Chicago, IL: University of Chicago Press, 1986, forthcoming.

Obstfeld, Maurice, "Capital Controls, the Dual Exchange Rate and Devaluation, NBER Working Paper Series No. 1324, April 1984.

Persson, Torsten, "Real Transfers in Fixed Exchange Rate Systems and the International Adjustment Mechanism", Journal of Monetary Economics 13, (May 1984): 349-69.

and Lars E.O. Svensson, "International Borrowing and Time-

Consistent Fiscal Policy", Scandinavian Journal of Economics 87, 1985. Stockman, Alan C., "A Theory of Exchange Rate Determination", Journal of Political Economy 86, (August 1980): $673 \rightarrow 98$. and Alejandro Hernandez D., "Exchange Controls, Capital Controls, and International Financial Markets", NBER Working Paper Series, No. 1755, October 1985.

Swoboda, Alexander, K., "The Dual Exchange Rate Systems and Monetary Independence", in Robert $z$. Aliber (ed.), National Monetary Policies and the International System, University of Chicago Press, 1974. van Wijnbergen, Sweder, "Capital Controls and the Real Exchange Rate," unpublished manuscript, October 1985. 